\title{
The Effect of Shoulder Flexion Angles on the Recruitment of Upper-extremity Muscles during Isometric Contraction
}

\author{
Jeheon Moon, PhD, ST ${ }^{1)}$, Insik Shin, $\mathrm{PhD}^{1)}$, Myoungsoo Kang, PhD, $\mathrm{ST}^{1)}$, \\ Yeonghun Kim, PhD, $\mathrm{ST}^{2)}$, Kunwoo Lee, $\mathrm{PhD}^{2)}$, Jaewoo Park, $\mathrm{PhD}^{3)}$, \\ Kyungnam Kim, PhD, $\mathrm{ST}^{3)}$, Daenie Hong, $\mathrm{PhD}^{3)}$, Dohoon Koo, $\mathrm{MS}^{4)}$, \\ DAVID O'SUllivan, $\mathrm{PhD}^{5)^{*}}$ \\ 1) Biomechanics Laboratory, Department of Physical Education, Seoul National University, Republic \\ of Korea \\ 2) Human-Centered CAD Laboratory, Department of Mechanical and Aerospace Engineering, Seoul \\ National University, Republic of Korea \\ 3) Mechatronics and Field Robotics Laboratory, Department of Mechanical Engineering, Korea \\ University, Republic of Korea \\ 4) Department of Rehabilitation and Assistive Technology, Korea National Rehabilitation Center \\ Research Institute, Republic of Korea \\ 5) Department of Sport Science, Chung-Ang University: 72-1 Daedeok-myeon, Anseong-si, \\ Gyeonggi-do 456-756, Republic of Korea
}

\begin{abstract}
Purpose] The purpose of this study was to investigate the differences in muscle activation patterns of the biceps brachii (BB) and flexor carpi radialis (FCR) muscles, while measuring the resultant force (RF) at different shoulder flexion angles. [Subjects] Thirteen healthy males (age 24.85 \pm 3.4 years, weight; $77.8 \pm 7.9 \mathrm{~kg}$; height, $1.7 \pm 0.05 \mathrm{~m}$ ) were enrolled in this study. [Methods] The resultant force was measured by a force transducer. The elbow angle remained constant and the flexion shoulder angle was changed $\left(30^{\circ}, 45^{\circ}, 60^{\circ}, 75^{\circ}\right.$ and $\left.90^{\circ}\right)$. [Results] The results of the surface EMG show the largest muscle activities occurred at a shoulder flexion of $75^{\circ}$ for BB and $90^{\circ}$ for FCR. The largest resultant force was measured at a shoulder flexion angle of $75^{\circ}$. We conclude, that when performing the biceps curl exercise using an arm curl machine, the shoulder should be flexed at $75^{\circ}$ to maximize the focus of the exercise for the BB. [Conclusion] These results are useful from the perspective of design as they highlight the differences in the muscle activation of BB and FCR with postural change. Ultimately this knowledge can be used in the design of rehabilitation training for the shoulder as they show that posture can affect muscle activation.
\end{abstract}

Key words: Biceps brachii, Flexor carpi radialis

(This article was submitted Apr. 2, 2013, and was accepted May 29, 2013)

\section{INTRODUCTION}

For the last couple of decades weight training has become increasingly popular due to its well-documented numerous benefits, such as increasing muscular strength and raising resting metabolism rates ${ }^{1)}$. According to Nelson, in a review article about the physical activity and public health of older adults, some of the benefits of resistance exercise include improvement of physical fitness, management and prevention of diseases caused by sedentary lifestyles, reduction of chronic health conditions and unhealthy weight gain ${ }^{1)}$. It is believed by personal trainers that the use of weight training machines are easier to learn than free weights. Also, weight training machines help the maintenance of good posture, and thus, are safer. The advantages and disadvantages of

${ }^{*}$ To whom correspondence should be addressed E-mail: tkdnutter@yahoo.com using weight training machines rather than free weights are well-established ${ }^{2,3)}$. Jones et al. investigated and compared the kinetic and kinematic variables of the power clean exercise using free weights and machine resistance ${ }^{4)}$. Their results demonstrate that both kinetic and kinematic variables were significantly different. While the maximum strength was significantly greater for the free weight condition, the average and peak velocities were significantly higher for the machine condition.

Isometric exercises have become popular and have been regularly and successfully implemented by physiotherapists for the rehabilitation of knee flexors and other muscles after surgery ${ }^{5}$. Isometric exercises are especially useful as they can provide a controllable and safe training environment for patients that have limited range of motion of the joints, and reduce the risk of pain and re-injury during exercise ${ }^{6}$. Furthermore, Hagberg showed there were no significant differences in the endurance times and the contraction levels 
sustained during isometric exercises compared to dynamic exercises $^{7}$.

It was shown in a study by Oliveria that the trunk and upper arm position can affect the muscle integrated EMG activation levels ${ }^{8)}$. In their study surface EMGs were recorded of the classic dumbbell biceps curl, inclined dumbbell curl and dumbbell preacher curl were presented and compared. The inclined dumbbell curl and the classic dumbbell biceps curl produced similar surface EMG activation levels, and both conditions isolated the biceps muscle more than the dumbbell preacher curl. To our knowledge, there have been no published studies investigating the effect of shoulder flexion angle on the muscles activated while performing a biceps curl. Thus, the purpose of this experiment was to investigate the differences in muscle activation patterns of isometric dumbbell curls among different trunk and upper arm postures.

\section{SUBJECTS AND METHODS}

Thirteen healthy male subjects participated in this study (age, $24.8 \pm 3.4$ years; weight, $77.9 \pm 7.9 \mathrm{~kg}$; height, $1.70 \pm 0.05$ $\mathrm{m})$. All subjects had more than one year of weight training experience and were right-handed. Prior to the start of the experiment, the subjects were given a full explanation of the purpose and experimental procedure, and signed Institutional Review Board consent forms to comply with the ethical standards of the Declaration of Helsinki (1975, revised 1983).

All subjects warmed up by light stretching and their skin was prepared ${ }^{9)}$. Two circular Ag-AgCl pre-gelled electrodes, (20 $\mathrm{mm}$ in diameter, $20 \mathrm{~mm}$ inter-electrode distance) were positioned on the biceps brachii (BB) (long head) and flexor carpi radialis (FCR) muscles following the Surface EMG for Non-Invasive Assessment of Muscles (SENIAM) recommendations ${ }^{10,11)}$. MVC testing was performed on a specially designed table and chair that were constructed for this study. For the BB MVC test, the trunk was strapped to the chair and the shoulder angle was fixed at an angle of $90^{\circ}$, directing the greatest exertion of force toward the subject's body. In the FCR MVC test, the forearm was held in position on the table, directing the greatest exertion of force upwards. During performance of the trials at the various shoulder angles $\left(30^{\circ}, 45^{\circ}, 60^{\circ}, 75^{\circ}\right.$ and $\left.90^{\circ}\right)$ a TELEMYO $2400 \mathrm{~T}$ G2 system (gain $=1000$, band-pass $=15-500 \mathrm{~Hz}$; Noraxon, USA) was used to record the data. The force was measured by a 6-axis force/torque sensor (Nano25, ATI Corp. Canada) installed on a haptic-based resistance-training machine built by the research team ${ }^{12}$ ). Surface EMG and force were synchronized through a 16-bit A/D converter (DAQ card AI-16XE-50, National Instruments, TX, USA). Trial positions were executed in a random order according to a table of random numbers. There was a three-minute break between each MCV trial and a two-minute break between each main experimental trial ${ }^{8)}$.

The study was conducted over a period of two days to increase the validity of the data, and all sEMG data were converted to root mean square (RMS), following the recommendations of previous research ${ }^{13)}$. To observe the changes in the neuromuscular activities of BB and FCR at the different shoulder angles, all sEMG data were obtained using an FIR band-pass filter ( $80-250 \mathrm{~Hz})$ and FIR high-pass filter $(10 \mathrm{~Hz})$ according to SENIAM recommendations. The sEMG data were rectified and the RMS were calculated for smoothing, then normalized with the MVC.

$$
\mathrm{RMS}_{\text {deg }}=\sqrt{\frac{1}{\mathrm{~T}_{2}-\mathrm{T}_{1}} \int_{\mathrm{T}_{1}}^{\mathrm{T}_{2}}[(\mathrm{x})]^{2} \mathrm{dt}}
$$

$\mathrm{RMS}_{\mathrm{deg}}=$ root mean square at the shoulder angle of deg, and $\mathrm{x}$ is the raw sEMG.

$\mathrm{T}_{1}$ and $\mathrm{T}_{2}=$ the start and end times, respectively.

The force was calculated using the formula shown below. All the force points were normalized to the maximum value for comparison.

$$
\mathrm{F}_{\text {force }}=\sqrt{\mathrm{F}_{\mathrm{x}}^{2}+\mathrm{F}_{\mathrm{y}}^{2}}
$$

$F_{\text {force }}$ is the resultant force, $F_{x}$ and $F_{y}$ are the forces exerted in the anteroposterior and vertical directions, respectively

All data were processed using the RMS method, and sEMG, MVC, and RF data were normalized to the maximum values. One-way ANOVA (Muscle Type $\times$ Degree) was used for the statistical analysis, and Tukey's post-hoc test was conducted on the data of the angles showing significant differences. The level of significance was chosen as $\mathrm{p}=0.05$. Statistical analyses were performed using a commercial statistics software program (SPSS v. 19.0, IBM).

\section{RESULTS}

Surface EMG showed the largest force of $115.65 \%$ and $88.80 \%$, respectively, at a shoulder flexion of $75^{\circ}$. The largest FCR activity $90.57 \%$, was at a shoulder angle of $60^{\circ}$. The results are shown in Table 1.

To investigate the differences among angles, Tukey's post-hoc test was performed. The results indicate that BB showed significant differences between $60^{\circ}$ and $90^{\circ}$, between $75^{\circ}$, and $30^{\circ}$, and $90^{\circ}(\mathrm{p}<0.05, p<0.01)$. The FCR results showed no significant differences between any angles. The mean and standard deviation values of RF at the different shoulder angles showed statistically significant results between $75^{\circ}$ and $30^{\circ}, 45^{\circ}(\mathrm{p}<.01)$ and between $90^{\circ}$ and $30^{\circ}$, $45^{\circ}(\mathrm{p}<.05)$. These results, along with the mean values of

Table 1. Mean (SD) of normalized surface EMG and force at various shoulder flexion angles

\begin{tabular}{cccc}
\hline \multirow{2}{*}{ Degree } & \multicolumn{2}{c}{ Surface EMG } & \multirow{2}{*}{$\begin{array}{c}\text { Force Sensor } \\
(\mathrm{N})\end{array}$} \\
\cline { 2 - 3 } & BB (\%) & FCR $(\%)$ & $72.5(9.2)$ \\
40 & $93.8(16.4)$ & $85.0(14.8)$ & $71.6(11.9)$ \\
60 & $100.6(25.9)$ & $86.4(21.4)$ & $84.1(12.3)$ \\
75 & $109.7(16.93)$ & $90.6(16.5)$ & $88.8(11.7)$ \\
90 & $115.6(22.4)$ & $89.0(17.1)$ & $87.2(14.3)$ \\
\hline
\end{tabular}


$\mathrm{BB}, \mathrm{FCR}$, and RF at the different shoulder angles, were normalized by RMS.

\section{DISCUSSION}

The force-length relationship of a muscle is defined as the maximal force obtained in a series of discrete contractions performed at different muscle (fiber and sarcomere) lengths ${ }^{14)}$. In most biomechanical muscle models, the submaximal force-length relationship is a linearly scaled version of the maximal force-length relationship ${ }^{14)}$. For skeletal muscles, the size of the force differs as a function of the muscle contraction type (sub-maximal contraction or maximal contraction) and the degree of flexion ${ }^{15}$.

In a computer simulation by Murry et al., the relationship between the length of the moment arm and force that could be generated at different positions of the elbow and forearm was investigated and compared ${ }^{16)}$. They concluded that the moment arm is maximized for the biceps when the arm is in an extended position with the forearm in supination. They also showed that the peak biceps supination moment arm decreases as the elbow angle is extended. Some researchers have investigated the degree of activation of $\mathrm{BB}$ and FCR by executing isokinetic and isometric exercises according to the change in the elbow angle, and it has been reported that these activations are affected by the type of the muscle contraction and the change in the angle ${ }^{17}$. In addition, in another study, the forces exerted in eight directions and the activation of muscles in five postures on the vertical axis were examined ${ }^{17)}$. These previous studies were mainly performed to explain the relationship between the force exerted by the upper arm in the vertical axis and its effect on muscle activation and conclusions were drawn about the control of the muscles from a neuromechanical perspective, without any advice on the practical implementation of this knowledge of these relationships.

In contrast, studies similar to ours have been conducted to investigate the generation of muscle activation by training when the forearm exerts force in the perpendicular direction, as in the curl motion. They have reported that the degree of activation of BB differs with different types of dumbbell curl motion and muscle contraction ${ }^{18)}$. The differences in the degree of activation of the BB can be understood by the surface EMG-torque relationship, which shows a non-linear increase in activation levels. The reason for the non-linear increase is that $\mathrm{BB}$ is used not only for flexion but also for supination ${ }^{14,19)}$.

The results of our study indicate that a shoulder angle of $75^{\circ}$ is the most effective at stimulating the BB and generating the highest force. For $\mathrm{BB}$, the $75^{\circ}$ shoulder angle had a surface EMG value that was significantly different from the values of $30^{\circ}$ and $90^{\circ}$. This means that this posture may be considered ideal for exercising or the design of a BB curl exercise machine. Our results, supported by Langenderfer et al., state that the ideal angle-torque relationship at the elbow joint is between $70^{\circ}$ and $80^{\circ}$ of shoulder flexion ${ }^{20)}$. Force showed statistically significant differences at shoulder flexion angles of $30^{\circ}$ and $45^{\circ}$.

\section{ACKNOWLEDGEMENT}

This research was supported by the Basic Science Research Program through the National Research Foundation of Korea (NRF) funded by the Ministry of Education, Science and Technology (2012-0001645).

\section{REFERENCES}

1) Nelson ME, Rejeski WJ, Blair SN, et al.: Physical activity and public health in older adults: recommendation from the American College of Sports Medicine and the American Heart Association Circulation. Med Sci Sports Exerc, 2007, 116: 1094-1105.

2) Harman E: The biomechanics of resistance exercise. In: Baechle TR, Earle RW. Essentials of strength training and conditioning, 2nd ed. Champaign: Human Kinetics, 2000.

3) Holcomb WR: Effect of training with neuromuscular electrical stimulation on elbow flexion strength. J Sport Sci Med, 2006, 5: 276-281.

4) Jones RM, Fry AC, Weiss LW, et al.: Kinetic comparison of free weight and machine power cleans. J Strength Cond Res, 2008, 22: 1785-1789. [Medline] [CrossRef]

5) Mohamed O, Perry J, Hislopd H: Synergy of medial and lateral hamstrings at three positions of tibial rotation during maximum isometric knee flexion. Knee, 2003, 10: 277-281. [Medline] [CrossRef]

6) Bayram U, Vasfi K, Serkan B: Effects of obesity on inpatient rehabilitation outcomes following total knee arthroplasty. Physiotherapy, 2008, 94: 198-203. [CrossRef]

7) Hagberg M: Muscular endurance and surface electromyogram in isometric and dynamic exercise. J Appl Physiol, 1981, 51: 1-7. [Medline]

8) Oliveira LF, Matta TT, Alves DS, et al.: Effect of the shoulder position on the biceps brachii EMG in different dumbell curls. J Sport Sci Med. 2009, 8: $24-29$.

9) Hermens HJ, Freriks B, Disselhorst-Klug C, et al.: Development of recommendations for SEMG sensors and sensor placement procedures. J Electromyogr Kinesiol, 2000, 10: 361-374. [Medline] [CrossRef]

10) Ahamed NU, Sundaraj K, Ahmad RB, et al.: Analysis of the effect on electrode placement on an adolescent's biceps brachii during muscle contractions using a wireless EMG sensor. J Phys Ther Sci, 2012, 24: 609-611. [CrossRef]

11) Stegeman D, Hermens H: Standards for surface electromyography: The European project Surface EMG for non-invasive assessment of muscles (SENIAM). Línea). Disponible en: http://www. med. uni-jena. de/motorik/ pdf/stegeman. pdf (Accessed Mar. 3, 2013)

12) Park JW, Kim KN, Hong DH: Haptic-based resistance training machine and its application to biceps exercises. Int J Prec Eng Manuf. 2011, 12: 21-30. [CrossRef]

13) Ahmadi S, Sinclair PJ, Foroughi N, et al.: Electromyographic activity of the biceps brachii after exercise-induced muscle damage. J Sport Sci Med, 2007, 6: 461-470.

14) van Zuylen EJ, Gielen CC, Denier GJ: Coordination and inhomogeneous activation of human arm muscles during isometric torques. J Neurophysiol, 1988, 60: 1523-1548. [Medline]

15) Hansen EA, Lee HD, Barrett K, et al.: The Shape of the force-elbow angle relationship for maximal contractions and sub-maximal electrically induced contractions in human elbow flexors. J Biomech, 2003, 36: 17131718. [Medline] [CrossRef]

16) Murray WM, Delp SL, Buchanan TS: Variation of muscle moment arms with elbow and forearm position. J Biomech, 1995, 28: 513-525. [Medline] [CrossRef]

17) Kasprisin JE, Grabiner MD: Joint angle-dependence of elbow flexor activation levels during isometric and isokinetic maximum voluntary contraction. Clin Biomech (Bristol, Avon), 2000, 15: 743-749. [Medline] [CrossRef]

18) Jan Nijhof E, Gabriel DA: Maximum isometric arm forces in the horizontal plane. J Biomech, 2006, 39: 708-716. [Medline] [CrossRef]

19) Dupont L, Gamet D, Perot C: Motor unit recruitment and EMG power spectra during ramp contractions of a bifunctional muscle. J Electromyogr Kinesiol, 2000, 10: 217-224. [Medline] [CrossRef]

20) Langenderfer J, LaScalza S, Mell A, et al.: An EMG-driven model of the upper extremity and estimation of long head biceps force. Comput Biol Med, 2005, 35: 25-39. [Medline] [CrossRef] 